\title{
El embajador de Juan Antonio Vera y Figueroa (1620) y su difusión editorial española*
}

\section{El embajador of Juan Antonio Vera y Figueroa (1620) and its Spanish Editorial Diffusion}

\section{Ana Vian Herrero}

Instituto Universitario Menéndez Pidal

Universidad Complutense de Madrid

ESPAÑA

avihe@ucm.es

[Hipogrifo, (issn: 2328-1308), 8.2, 2020, pp. 817-829]

Recibido: 26-01-2020 / Aceptado: 17-02-2020

DOI: http://dx.doi.org/10.13035/H.2020.08.02.48

Resumen. El embajador (Sevilla, Francisco de Lyra, 1620) de Juan Antonio Vera y Figueroa circuló posiblemente manuscrito por las cortes española y flamenca desde 1618, y se tradujo total o parcialmente varias veces al francés y al italiano. Se desentraña aquí la difusión impresa del original español, intentando corregir errores acumulados en las referencias catalográficas; el objetivo es llegar a confirmar, uno a uno, los testimonios que realmente sobreviven, aclarando a qué edición corresponden. Razones literarias e ideológicas apoyan el estudio bibliográfico y se concluye sobre una posible edición planificada para una doble difusión, en dos emisiones. Descartada una edición de 1621, la difusión del texto español se circunscribe a la edición de Sevilla, 1620, y a otra edición sevillana contrahecha identificada por mí gracias a un ejemplar mútilo conservado en la Biblioteca del Hospital Real de la Universidad de Granada, cuyo año real de impresión y taller desconocemos.

Palabras clave. Juan Antonio Vera y Figueroa; El embajador; difusión editorial; análisis bibliográfico, edición contrahecha.

* Este trabajo se ha realizado en el marco del proyecto I+D «Dialogyca: Del manuscrito a la prensa periódica: estudios filológicos y editoriales del Diálogo hispánico en dos momentos», PGC2018-095886-B-100 (MCI/ AEI/ FEDER), con sede en el Instituto Universitario Menéndez Pidal de la Universidad Complutense. 
Abstract. El embajador by Juan Antonio Vera y Figueroa (Sevilla, Francisco de Lyra, 1620), circulated possibly handwritten in the Spanish and Flemish courts since 1618. The work was totally or partially translated several times into French and Italian. The printed diffusion of the Spanish original is unraveled here, trying to amend accumulated errors in some references of catalogues; the goal is to confirm, one by one, the witnesses that really survive, clarifying to which edition they correspond. Literary and ideological reasons support the bibliographical analysis, that concluded on a possible planned edition for a double diffusion in two issues. Discarded a 1621 edition, the printed diffusion of the Spanish text is limited to the edition of Seville 1620 and to the counterfeit Sevillian edition identified by me thanks to an imperfect copy preserved in the Library of the Royal Hospital of the University of Granada, whose real year of printing and printer are still unknown.

Keywords. Juan Antonio Vera y Figueroa; El embajador; Editorial diffusion; Bibliographical analysis; Counterfeit edition.

El embajador (Sevilla, Francisco de Lyra, 1620)' , obra del amigo de Lope de Vega, Juan Antonio Vera y Figueroa (1583-1658) es uno de los los diálogos formativos más interesantes del final del reinado de Felipe III, extenso texto político organizado en cuatro libros, que en ese momento conecta, como otros diálogos de las mismas fechas, con el proyecto educativo de Olivares para la aristocracia -sector al que a la sazón debía pertenecer el diplomático de carrera-. Es un ejemplo de prosa clasicista de altura² ${ }^{2}$ escrito cuando Vera era aún secretario del diplomático de Felipe III don Gómez Suárez de Figueroa, III duque de Feria -quien lo familiarizó con el oficio-, y probablemente pensando en adquirir él mismo la condición de diplomático ${ }^{3}$.

En su dedicatoria «A don Felipe IIl» el autor se refiere a «estos discursos que procuran constituir el Embaxador», que «no parecen humildes, pues a subir tanto se atreven». Las Aprobaciones (del jesuita Diego Granado y del cronista regio Antonio de Herrera) insisten en la utilidad para los del oficio y en la reputación que puede obtener la nación. La obra se concibe en buena pero no total medida como manual

1. Esta edición sevillana contiene, además de algunas erratas que ahora no menciono, diversos particularismos de lengua interesantes, aunque no todos necesariamente del autor: andalucismos gráficos como ceceo o excepcionalmente seseo; algún vulgarismo, o formas analógicas que se repiten con la insistencia suficiente como para apreciar su particularidad y no considerarlas errata de impresión; trueques o indefiniciones en el uso del artículo sin marca de masculino o femenino en el étimo, etc. Hay reimp. facs. de 1947, con apunte preliminar de J. M. López Balboa (Catálogo Colectivo del Patrimonio Bibliográfico Español, cit. en adelante por sus siglas: CCPBE, 000890822-2 y 000946106-X) y ed. facsímil reciente (2010) -a nombre de don Juan Antonio de Vera y Zúñiga-, huérfana de cualquier estudio y por completo prescindible, ya que el texto se lee cómodamente en red en el ejemplar conservado por la Biblioteca Histórica Marqués de Valdecilla, sign. BH FOA $1730<$ <ttp://ucm.on.worldcat.org/ oclc/1024925359>, del que hereda incluso sus errores de digitalización (entre otros detalles, faltan fols. $31 \mathrm{v}-32 \mathrm{r}$, presentes en cambio en los ejemplares que custodian BNE y USAL). Cito por este ejemplar de la BHMV, con modernización gráfica limitada a fenómenos sin trascendencia fonética.

2. Para distintas formas de concebir el género en el siglo XVII avanzado, Gómez, 2015

3. Merluzzi, 2016, § 38 , 
de uso y de cita para el diplomático, ya que «la oratoria es parte esencial en el legado» y el autor «procura probar con razones y exemplos» (I, fol. 1v) su construcción. Pineda ha destacado la importancia de la elocuencia en el texto ${ }^{4}$. No se encuentra, en todo caso, en la obra solo erudición de modelos tradicionales, porque eso no le hubiera asegurado el éxito ${ }^{5}$. El análisis de las propuestas formales y las líneas básicas de la argumentación, junto a su actualidad candente -aspectos que son objeto de trabajo independiente ${ }^{6}$-, apoyan y confirman una posible difusión peculiar del texto. De cualquier modo, la elección del género, precisamente para alejarse del tratado, es con bastante probabilidad una de las razones de su éxito ${ }^{7}$ y de su amplio dominio en el seiscientos europeo, junto con las deudas de distinto tipo a diálogos de referencia en el periodo, como II messaggiero de Tasso o, en especial, el De constantia de Justo Lipsio. Aunque la mayoría de los ejemplos que Vera acopia son puros fundamentos de experiencia, sabiduría experimental que la historia de la diplomacia había sistematizado, a alguno pareció directamente plagio ${ }^{8}$. Un modelo muy citado, la Politica de Lipsio, nos avisa de la difusión de un Lipsio enmendado y expurgado9. El diálogo de Vera, de clara factura humanística y tono señorial y ligero, delata a un espíritu fino, culto, que, aun mostrando conocer las relaciones internacionales y los precedentes quinientistas de literatura diplomática, se aparta de ellos deseando hacer una obra más práctica, no de vocación platónica sino de consulta técnica, fruto de una cuidadosa preparación. La forma francesa de traducirlo, añadiendo al título el adjetivo 'perfecto', lo asoció demasiado al género de los diálogos y tratados formativos de cuño ciceroniano (el perfecto príncipe, caballero, cortesano, el magistrado ideal, etc.) y por tanto trivializó su alcance, como vio en su finísimo estudio B. Cinti ${ }^{10}$. El texto de Vera no servía solo para que el diplomático amenizara una conversación o brillara en ella por sus alardes eruditos; para eso había mucha literatura disponible. Para el conde de la Roca tan importante como el propósito formativo (propio de Tasso cuarenta años antes) o la contribución lipsiana, del aprecio del conde-duque, es la faceta de prontuario que el diálogo cultiva:

[...] demás que nuestro argumento no es formar al príncipe en el mando, sino al embaxador en la obediencia. La instrucción es una carta de marear por donde ha de ir guiando el embaxador su derrota [i. e., su 'derrotero, camino, rumbo', en acepción marinera]... (El Embaxador, III, fol. 12v).

4. Pineda, 2015

5. Merluzzi, 2016, §11.

6. De los distintos aspectos formales del diálogo que ahora dejo de lado, el tratamiento retórico del espacio es, quizás, el indicador más claro de una posible doble difusión del texto: Vian Herrero, en prensa a. 7. López-Cordón, 2015, §23.

8. Ginarte González (1990, p. 38) recuerda el reproche de don Antonio Hurtado de Mendoza por la influencia de Lipsio, del que considera al Embaxador copia servil. Esta denuncia se analiza en FernándezDaza, 1995, pp. 125-126. Para la sistematización histórica de la diplomacia del periodo sigue siendo imprescindible Mattingly, 1955.

9. Lo comunica el mismo personaje de Julio: «El sentimiento de Lipsio fue muy bueno siempre, menos en aquella parte de sus escritos que la Inquisición tiene enmendada [...]» (El Embaxador, II, fol. 89r). La Politica, muy influyente en España, Francia y Alemania, circuló en toda Europa en ambas versiones, pero aquí se refiere a la versión 'católica' y anotada, editada en 1596 en Amberes.

10. Cinti, 1966, p. 133; Ochoa Brun, 2006, VII, p. 390; Merluzzi, 2016, §40. 
Se trataba, pues, de orientar de doble manera, teórica por un lado, por otro práctica y sistemática, su día a día profesional, y así cubrir una necesidad ineludible en la Europa del periodo ${ }^{11}$.

Los cuatro libros, precedidos de sus respectivos epítomes («Sumario. De lo que contiene este discurso»), se dividen en dos partes, dos a dos, también como piezas editoriales, quizás porque aspiraran a poderse vender independientemente ${ }^{12}$. Van unidos por parejas en paginación (el II acaba en fol. 151r, el III empieza en fol. 1r y el IV termina en fol. 131r), y al final la «Tabla alfabética de las cosas notables de este libro» de cada una de ambas partes, sin foliar, se redacta también por separado ( I y II; III y IV ${ }^{13}$. La razón más clara es que la materia es más práctica en los dos últimos, III y IV, más centrada en reglar de forma metódica consejos para la labor diplomática antes y durante el desempeño de una embajada. Los dos primeros discursos, más teóricos - pese a su interés también práctico en cuestiones procedimentales de los oficios de gobierno-, cumplen una función distinta a los dos últimos ${ }^{14}$. Además en estos asoma el amor de la patria española de forma más diferenciada, lo que explica también que las traducciones de la obra fueran reducidas, aunque es tema que merece una atención que aún no ha recibido: nada bueno diría a los franceses la argumentación de la precedencia española sobre la francesa - salvo para saber defenderse mejor-, o las justificaciones de la retención española del reino de Navarra. Expone las herejías de varias naciones y la específica de Bohemia. Al dar noticias sobre diversos reinos y repúblicas (Inglaterra, «República de los suizos», Francia15, Venecia, Saboya y el Piamonte, Génova y sus gobiernos)

11. Mattingly, 1955, pp. 183-184.

12. La ayuda prestada por Mercedes Fernández Valladares para orientarme en esta selva textual (que incluye las traducciones) ha sido decisiva, muy superior a la que la amistad o la comunidad de profesión y proyecto investigador pudieran obligar. Mi gratitud solo puede ser correlativa. Sobre el tema tiene ella en preparación un artículo definitivo y están en prensa en DialogycaBDDH <http://www.dialogycabddh. es/> sus espléndidas descripciones del registro de El embajador de Vera (núm. 325).

13. También había percibido este detalle Pineda, 2015, p. 488, n. 7.

14. A ello parece apuntar también el análisis material de la secuencia de signaturas de su fórmula colacional, rara vez reflejada correctamente en las descripciones catalográficas: 4. ‥- [ ]4 A-T8; Aa-Qq8 Rr-Zz4.- 4 h., I-151 f., 1 h. en blanco, I-131 f., 25 h., la última de ellas en blanco. No parece casual el hecho de que los dos primeros discursos abarquen una secuencia de diecinueve cuadernos (en cuartos de a dos), interrumpida en el cuaderno T, cuya última hoja T8 se dejó además en blanco como separación de las dos partes y protección final de la primera, reiniciando otra serie alfabética para los discursos tercero y cuarto. La Tabla final se cierra igualmente con una hoja en blanco como protección. Para la distribución exenta de los discursos tercero y cuarto posiblemente se añadiría por delante el primer cuaderno sin signatura [ ]4, que contenía el frontispicio, la estampa calcográfica de Felipe III rodeado de nueve empresas alusivas a las virtudes del buen embajador y los documentos de preliminares, por lo que no habrían necesitado planificar una portada interna específica para ellos, superflua además en los volúmenes de difusión conjunta de los cuatro diálogos. De esta interpretación tipobibliográfica se derivaría la consideración de dos emisiones, planificadas para una doble difusión, conjunta de los cuatro discursos [emisión A] y exenta solo con los dos finales [emisión B]. Para todo ello, vease la descripción de Mercedes Fernández Valladares, en DialogycaBDDH (en prensa).

15. Frente al desarrollo fácil de la natural antipatía, hay que destacar algún indicio de neutralidad intelectual de Vera: Ludovico elogia a Francia y a Francisco I por su capacidad para regenerar las letras: «...y por esta razón [...] están tan válidas en aquel reino las letras, particularmente el estudio de las leyes, 
explica también sus conflictos y motivos de litigio, aunque su perspectiva es la habsbúrgica. Cada una de las partes puede, en suma, tener destinatarios diferentes: Ios lectores de los discursos III y IV han de ser o proespañoles o querer estudiar al enemigo de cerca, aunque ahí se contenga información valiosa sobre las formas de gobierno y religión de varios reinos y repúblicas occidentales, del Papado y del Imperio; se comprende, pues, que esa necesidad no escapara a impresores avispados. El asunto, que requeriría un interesantísimo y necesario trabajo comparado, está por estudiar seriamente, como a continuación veremos.

Pese a esas posibilidades distintas de difusión, no proliferaron las ediciones españolas. Aparte de esta princeps sevillana de 1620, se menciona una contrahecha del mismo año y Palau habla de otra edición de 1620, impresa en Madrid; Nicolás Antonio citaba solo una sevillana de 1621 cuya existencia no se ha confirmado (probable errata simple por 1620) ${ }^{16}$, noticia que llega a Graesse y pasa luego a otros mencionados más adelante. El embrollo de referencias catalográficas erróneas es acumulativo, de modo que conviene detenerse un momento para intentar poner en claro esta transmisión y apuntar unas líneas que permitan llegar a confirmar los testimonios que realmente sobreviven.

Nicolás Antonio había errado no solo en la fecha supuesta de 1621 (por 1620) sino incluso en los nombres de los traductores italiano y francés ${ }^{17}$. J. G. Th. Graesse reproducía después la información vaga de Nicolás Antonio ${ }^{18}$, haciéndose eco además de la existencia de una segunda edición sevillana del mismo año 1620, tomada de Salvá ${ }^{9}$. En su primera edición, Palau registraba tanto la edición de Sevilla

deuda que debe reconocer la República de los literatos a Francisco Primero, que levantó esta facultad del estado de deshonor que poseían sus profesores al del honor que hoy poseen» (IV, fol. 99r). Es una idea que corre en la Francia del periodo: Petey-Girard, Polizzi y Tran, 2017.

16. Confirma que la errata se produce a la altura de Nicolás Antonio el hecho de que Tamayo de Vargas, Junta de libros, p. 462, s. v. Juan de Vera Vargas y Zúñiga, solo cita la edición de Sevilla, por Francisco de Lyra, 1620, 4. ${ }^{\circ}$ (no 1621).

17. N. Antonio, Bibliotheca Hispana Nova, 1783-1788, I, pp. 635-636, s. v. Ioannes Antonius de Vera et Zúñiga: «El embaxador: sive de legati munere. Hispali 1621, in 4.․ Italicum edidit, tacito Verae nomine, Mutius Zicatta, Venetiis 1646, in $4 .^{\circ}$. Gallicum quoque sub vero titulo N. Lamelot (sic), Parisiis apud Antonium de Sommaville 1635. 4. ${ }^{\circ}$ ». En versión española añade una errata más: «El Embaxador: o sobre la fundación del embajador. Publicado en Sevilla, en 1621, en $44^{\circ}$. Lo publicó en italiano, pero silenciando el nombre de Vera, Mutio Zicarta (sic), Venecia, en 1646, en 4.․ También en francés lo publicó con su verdadero título N. Lamelot (sic), París, en la imprenta de Antonio de Sommaville, en 1635, en 4. ${ }^{\circ}$ (N. Antonio, Bibliotheca Hispana Nova, p. 678).

18. Graesse, 1950, VII, pp. 278-279, s. v. Vera y Figueroa (ou Zúñiga), Juan Antonio de: «El Enbaxador. Sevilla, Franc. de Lyra 1620. in-4. ${ }^{\circ}$. Av. titre gr. et une pl. cont. des emblêmes. (2 I. 2 sh. Salva.). Il existe une seconde éd, sortie des mêmes presses dans la même année, imprimée sur du papier moins bon et sans le front. ni la pl. (2 I. 2 sh. Salva). Une $3^{\mathrm{e}}$ a paru ib. 1621. in-4. ${ }^{\circ}$. Il existe une trad. franc. intit.: Le parfait ambassadeur trad. de l'espagnol par le Sieur Lancelot. Sur la copie de Paris 1642. in.-12. (5 fr. 15 c. Du Fay). Leide, Haak 1709. 2 tom. in-8. ${ }^{\circ}$. (10 fr. Du Fay)».

19. Aunque sin la consideración de contrafacta, pues Graesse se limita a anotar, como se acaba de ver, la peor calidad del papel. En efecto, esa mención aparece por primera vez en el Catálogo de la Biblioteca de Salvá, donde se recogen en asientos sucesivos los dos ejemplares que se reservaron los selectos libreros para su colección: en el vol. II, núm. 4034, describen un ejemplar de la princeps sevillana, cuyas 
1620 -y la contrahecha de la misma ciudad y año, aunque sin mencionar que tomaba el dato de Salvá-, como una de Madrid, también de $1620^{20}$, pero nada decía del error de Nicolás Antonio. La segunda edición de Palau es de consulta imprescindible en este caso, porque amplía y aclara la información ${ }^{21}$. Lo más revelador es su sospecha sobre el error de Nicolás Antonio, pues no se conoce ejemplar ni noticia fiable de una edición de Sevilla 1621 y además los traductores están identificados. De hecho, tanto Simón Díaz como Domínguez Guzmán registran únicamente la edición sevillana de 1620, con su distribución de folios correcta ${ }^{22}$.

características coinciden con la fórmula colacional del ideal copy indicada arriba (mi nota 14), salvo en las hojas finales, pues dicen « 21 hojas para las Tablas con una blanca al fin», y añaden el comentario «esta es sin duda la edición genuina». En el siguiente núm. 4035, registran otro ejemplar con el mismo pie de imprenta: «Sevilla, Francisco de Lyra, 1620, 4. ${ }^{\circ}, 2$ hojas prels. á más de la portada que está impresa suelta, 151 hojas fols. para los dos Discursos primeros, 131 para el tercero y cuarto, y 20 hojas de Tablas», añadiendo el siguiente comentario: «La edición debió contrahacerse en el año que suena (i.e. 1620) ó poco después. Está hecha á plana i renglón con la otra hasta el fol. 41 inclusive del Discurso tercero: de allí en adelante ya tiene algunas diferencias de las cuales resultan al fin una página más. Es singular que no se rehicieran el frontis grabado y la lámina que le sigue, cuando se reprodujo hasta la fe de Erratas, que menciona muchas, corregidas ya en esta reimpresión, inferior a todo en la genuina». No compartimos la extrañeza de Salvá pues, aun tratándose de una edición contrahecha, es lógico que no se remedaran las estampas calcográficas por el encarecimiento y la dificultad que suponía; los ejemplares piratas podían hacerse pasar además por una tirada abaratada.

20. «El Enbaxador por don Ivan Antonio de Vera y Çuñiga. Seuilla, Francisco de Lyra, 1620, 4 , frontis grabado, 1 retrato, 2 hojas, 151131 fols., 21 hojas [...]. De El Embaxador corre otra edición contrahecha, a plana y renglón, pero sin las 2 láminas, Sevilla, Francisco de Lyra, 1620, 4. ${ }^{\circ}, 3$ hojas 151-131 fols. y 20 hojas. También corren ejemplares con frontispicio de Madrid 1620, 4. ${ }^{\circ}, 30$ a 35 pts.»; en Palau y Dulcet, 1927, VII, pp. 148-149 (en p. 148), s. v. Vera y Figueroa, Juan Antonio de.

21. Palau y Dulcet, 1948-1977 (2. a ed. corr. y aum.), XXVI, 1975, núms. 358982-358987. El núm. 358982 añade datos y corrige otros: «Vera y Figueroa (Juan Antonio de), Conde de la Roca, El Embaxador por don Ivan Antonio de Vera y Çuñiga..., Sevilla, Francisco de Lyra, 1620, 4. ${ }^{\circ}(19,5 \mathrm{~cm}$.), frontis grab., 1 retr. 2h. 151+31 [sic por 131] fols. dividido en dos partes. 5000 pts. Granata 1959, 20.000 pts. Rodríguez Muñoz 1971». Y sigue: «De El Embaxador corre otra edición contrahecha, a plana y renglón, pero sin las dos láms., Sevilla, Francisco de Lyra, 1620, 4. , 3 h. 151-131 fols. y 20 h., 1000 pts. Truebols 1955. También corren ejemplares con frontispicio de Madrid $16204 .^{\circ} 30$ a 35 pts. Cita N. Antonio esta obra con vaguedad y equivocación, refiriéndola a 1621. Hay ejemplar en la Biblioteca provincial de Sevilla, otro en la Univ. de Madrid, y otro en las de Zaragoza y Huesca». De la primera edición de Sevilla 1620 hay facsímil de Madrid 1947 con un breve preliminar de José Manuel López Balboa (Palau, núm. 358983). El ejemplar de la Biblioteca provincial de Sevilla no corresponde a la 1. ${ }^{a}$ edición sevillana sino a su facsímil de 1947. 22. Simón Díaz, 1972, núm. 1437; y Domínguez Guzmán, 1991, núm. 609 (con remisión además a Escudero y Peroso, 1894, núm. 1206). 
Se conserva un número apreciable de ejemplares de la primera edición seviIlana ${ }^{23}$, varios de ellos accesibles en red ${ }^{24}$. La otra edición sevillana de 1620 que registra el CCPBE según parece no es completa25, sino que recogería solo las partes o discursos III y IV, aunque nada aclara al respecto dicho catálogo. Si, a la vista de

23. Copio los datos principales de la descripción del CCPBE, 000042768-3, pues en este caso procede tenerlos delante y extraer consecuencias: «Autor: Vera y Figueroa, Juan Antonio de I, Conde de la Roca (1583-1658). Título: El enbaxador / por don Iuan Antonio de Vera i Çuniga. Publicación: En Seuilla: por Francisco de lyra, 1620. Descripción física: [3], 151, [1] en bl., 131, [24] h., [1] en bl., [1] h. de grab.; 4. ${ }^{\circ}$. Notas: Sign.: [ ]3, A-T8, 2A-2Q8, 2R-2Z4. Notas: Port. grab. calc. arquitectónica. La h. de grab. es calc.: 'Alardo de Popma Sculpsit Hispali'». El mismo catálogo registra un total de veintiocho ejemplares localizados en diversas bibliotecas de Andalucía, Aragón, Castilla-La Mancha, Castilla y León, Cataluña, Comunidad Valenciana, Extremadura, Galicia y Madrid; sin embargo, no creo que todos correspondan realmente a esta edición. EI USTC, por su parte (núm. 5025653), registra hasta noventa ejemplares localizados, seis de los cuales en red, pero no hay rigor: entre los digitalizados atribuye, por ejemplo, al repositorio Hathi Trust el que custodia la Biblioteca Marqués de Valdecilla, biblioteca pionera en la digitalización del texto, y da por primera edición sevillana el de la Universidad de Granada, que, pese a lo que dice el catálogo, quizás - a falta de cotejo directo- sea más bien la contrahecha completa, aunque sin preliminares, lugar de edición o fecha, ni frontispicio ni grabado, al menos en el texto digital. Es decir, la información contenida en el CCPBE y el USTC debe aún ser corroborada ejemplar a ejemplar para llegar a tener datos fiables, pues en la actualidad se mezclan como si fueran lo mismo primera edición sevillana, supuesta edición sevillana contrahecha, edición madrileña, facsímil de 1947 y hasta a veces traducciones de época.

24. He manejado los ejemplares digitalizados que custodian la Biblioteca Marqués de Valdecilla de la UCM y la BNE, que también cotejé directamente en lugares concretos.

25. Corresponde a CCPBE, 000271996-7: «Autor: Vera y Figueroa, Juan Antonio de I, Conde de la Roca (1583-1658). Título: El enbaxador / por don luan Antonio de Vera i Çuniga comendador de la Barra en la Orden de S.Tiago [...] A Don Felipe III N.S glorioso Monarca, de España Enperador de las Indias. Publicación: En Seuilla: por Francisco de lyra, 1620. Descripción física: [3], 131, 24 h., 4. ․ Notas: El autor se normaliza como Juan Antonio de Vera y Figueroa. Notas: Port. calc. arquitectónica». Al registrar la materia/género se lee: «Vera y Figueroa, Juan Antonio de, I Conde de la Roca (1583-1658)-Discursos», lo que solo puede explicarse bien por una simplificación del tema del diálogo al catalogarlo -ya que el autor llama a sus libros «discursos»-, o bien por el protagonismo que adquieren los discursos en el libro IV (sobre todo). También puede tratarse de una confusión con otra obra de Vera, sus Discursos al Duque de Saboya sobre la protesta que hizo a Su Alteza el embajador de Francia, aunque texto mucho más breve y de índole muy distinta (que conserva, entre otras, la BNE). Según el registro del CCPBE se custodian testimonios de esta otra edición sevillana de 1620 en las bibliotecas Universitaria de Oviedo, de Castilla-La Mancha en Toledo, y de la Real Academia de Ciencias Morales y Políticas en Madrid. Solo el de Oviedo tiene 131 fols., según su opac: «Vera y Figueroa, Juan Antonio de. Título: El Enbaxador / por don Iuan Antonio de Vera I Çuniga comendador de la Barra en la Orden de S.Tiago... A Don Felipe III N.S. glorioso Monarca, de España Enperador de las Indias. Editorial: En Sevilla: por Francisco de Lyra, 1620. Descripción física: [3], 131, 24 h.; 4.․ Notas: El autor se normaliza como Juan Antonio de Vera y Figueroa Port. calc. arquitectónica Materias: Vera y Zúñiga, Juan Antonio de-Discursos (+) Autores: Lyra, Francisco de, imp.». El de Toledo posee, en cambio, una descripción idéntica a la de la primera edición, de 151+131 fols.; copio de su opac: «Autor: Vera y Zúñiga, Juan Antonio de. Título: El Enbaxador / por don Ivan Antonio de Vera I Çvniga comendador de la Barra en la Orden de S.Tiago ... A Don Felipe III. N. S glorioso Monarca, de España Enperador de las Indias. Editorial: En Sevilla: por Francisco de Lyra, 1620. Descripción física: [3], 151, [1] en bl., 131, 24 h., [1] h. de grab.; 4. ․ Notas: Sign.: []3, A-T8, 2A-208, 2R-2Z4. Port. calc. arquitéctonica. La h. de grab. calc.: 'Alardo de Popma sculpsit hispali'. Materias: Discursos. Política. Autores: Lyra, Francisco de.». Lo mismo ocurre con los dos ejemplares de la Academia de 
algún ejemplar, se corroborara esta suposición mía, sería una confirmación evidente de que El embajador se leyó y distribuyó por partes ${ }^{26}$.

Por su parte el USTC (The Universal Short Title Catalogue) registra bajo su referencia núm. 5036910 la edición de Madrid, [s. n.] 1620. Dice:

PRIMARY AUTHOR: Roca, Juan Antonio Vera Zúñiga y Figueroa, conde de la

SHORT TITLE: El embaxador.

IMPRINT: Madrid, s. n., 1620.

PLACE: Madrid

DATE: 1620

FORMAT: $8 .^{\circ}$

PP/FF: ff. [2] 151131 [20].

CITATION: IB B90219

LIBRARY COPIES:

Dresden (De), Sächsische Landesbibliothek

Santiago (Cl), Biblioteca Nacional de Chile BNCLF 8;(1028-29) Reservado

Santiago (Cl), Biblioteca Nacional de Chile BNCLF 8;(1028-31) Reservado

Toronto (Ca), Thomas Fisher Rare Book Library of the University of Toronto

Tübingen (De), Universitätsbibliothek

Venezia (It), Biblioteca nazionale Marciana.

Consultada la ficha catalográfica de cada uno de los ejemplares mencionados, y aunque no ha estado a mi alcance su consulta directa, es necesario advertir que los testimonios de la BN de Chile y de la Universidad de Toronto en principio sí podrían corresponder al registro de la edición madrileña, si bien no puede aún cerrarse la cuestión ${ }^{27}$. No ocurre lo mismo con el ejemplar de la Biblioteca Marciana, ni con

Ciencias Morales y Políticas. Deben, pues, discriminarse correctamente los datos del CCPBE, además de lo que advierto en la nota siguiente.

26. No obstante, conviene advertir que esa extensión limitada a solo 131 fols. que ofrecen algunos opacs (en la que parece ampararse la discriminación en el CCPBE de un registro específico para una tirada reducida a los dos últimos discursos), pudiera deberse a un simple error de colación apresurada, propio de catalogadores no especializados que toman como extensión total el último folio numerado del volumen, sin percatarse de la existencia de una doble foliación. De hecho, esto es lo que parece haber sucedido para el ejemplar de la Biblioteca de la Universidad de Oviedo (CEA-201), cuya comprobación agradezco al director de la Biblioteca, Ramón Rodríguez Álvarez, por mediación de Mercedes Fernández Valladares. También el ejemplar de la Biblioteca de Toledo 1-4847 presenta esta misma situación, según ha comprobado amablemente su bibliotecaria Carmen Toribio. En cuanto a los dos ejemplares de la Real Academia de Ciencias Morales y Políticas, solo ha sido posible consultar el 8726, que lleva las cuatro partes; en cambio el otro, con signatura 411, en proceso de localización por reorganización de los depósitos, figura registrado en el topográfico interno de esta biblioteca con una extensión de 131 fols. exclusivamente.

27. BNChile, Fondo General. Bóveda. 8; (1028-29) y 8; (1028-31): «Título: El embaxador. Autor: Roca, Juan Antonio de Vera y Zuñiga y Figueroa, conde de la, m. 1648. Materias: EMBAJADORES; EUROPA POLITICA Y GOBIERNO. Lugar y editor: Madrid: s. n. Fecha de publicación: 1620. Descripción física: [2], 151, 131, [20] h.; 21 cm. (8v). Idioma: Español». Sin embargo, resulta sospechosa la disonancia entre la indicación del formato -reducido con respecto a la edición princeps sevillana, sin que se incremente en número de folios, solo explicable por el recurso a una tipografía de cuerpo notoriamente menor- y la medida en centímetros, más concordante con un formato en $4 .{ }^{\circ}$. Por su parte, en la Thomas Fisher 
el de la Universitätsbibliothek de Tübingen, que corresponden a la primera edición sevillana según sus respectivos catálogos ${ }^{28}$. Por su parte, las entradas del catálogo de la Sächsische Landesbibliothek de Dresden no pertenecen a edición española alguna, sino a las traducciones francesa e italiana. El rigor brilla por su ausencia y queda pendiente contrastar una a una las informaciones mezcladas, equívocas o erróneas del USTC.

En resumen, en lo que concierne al original español, hay que descartar la existencia de una edición de 1621; la primera edición (completa y conservada) es la de Sevilla, Francisco de Lyra, 1620, que posiblemente fue planificada para una doble difusión, conjunta de los cuatro discursos y desglosada de los dos últimos, más orientados a la práctica; esta edición, a su vez, ha sido objeto de los dos facsímiles contemporáneos que se citaban al principio de este trabajo.

De la segunda edición sevillana de 1620, considerada contrahecha y cuyo año real de impresión y taller desconocemos, solo se ha podido tener confirmación, por ahora, de un ejemplar, incompleto aunque suficiente para corroborar la precisa noticia transmitida por Salvá citada arriba. En efecto, uno de los dos ejemplares conservados en la Biblioteca del Hospital Real de la Universidad de Granada, aunque mútilo de la portada y de la estampa calcográfica, así como carente de preliminar alguno, coincide en cuanto a su composición con las peculiaridades señaladas por Salvá29.

Rare Book Library of the University of Toronto: «El enbaxador. Vera y Figueroa, Juan Antonio de, conde de la Roca, 1588-1658. Imprint Madrid, 1620. Description [2], 151, 131, [23] leaves. Format(s) Book. Rare Book buc 00601. General note Title-page lacking. Catalogue key 1059889»; pero nótese la carencia de portada, en la que presumiblemente deberían figurar el lugar y fecha de impresión. En tanto no sea posible corroborar tales datos con la consulta directa de esos ejemplares, parece prudente el mayor escepticismo sobre esta edición madrileña.

28. Biblioteca nazionale Marciana, Venecia: «Inventario ANT 57146. Collocazione C 210C 109-110. Note: 1 v. (legato in 2 tomi). Provenienza: Contarini, Girolamo. Descrizione: Testo a stampa (antico). Monografia. El *enbaxador por don luan Antonio de Vera i Çuniga commendador de la Barra en la Orden de S. Tiago ... En Seuilla: por Francisco de Lyra, 1620. 151, [1], 131, [25] c., [1] c. di tav.; 4. Note: Prima edizione dell'opera, cfr. Palau y Dulcet, Manual del librero hispanoamericano, v 26, p. 133, n. 358981. Tavola con frontespizio architettonico inciso a bulino Segn.: A-T8 2A-2Q8 2R-2Z4. Anno pubblicazione 1620. Lingua spagnolo. Autore Vera Figueroa y Zúñiga, Juan Antonio de <1588-1658> Note e bibliografía. Editore Lyra, Francisco de. Codice SBN L01E015928. Luogo pubblicazione Siviglia. Impronta ade- s-e- o.o: Cagl (3) 1620 (A). Copia link: <http://polovea.sebina.it/SebinaOpac/.do?idopac=VEA2348022>. Por su lado, el ejemplar de la Tübingen Universitätsbibliothek, dice más escuetamente: «Titel: El enbaxador / por luan Antonio de Vera i Çúniga. Person: Vera y Figueroa, Juan Antonio de. Erschienen: Sevilla: F. de Lyra, 1620. Sprache: spanisch. Umfang: 151, 131 Bl. Standort: Bestellbestand - Rara-Raum. Signatur Hk 8.4».

29. Concretamente, el ejemplar A-001-253 accesible en red, con la siguiente colación, completada en lo concerniente a las hojas iniciales con la información ofrecida por Salvá ( $44 .{ }^{\circ}, 2$ hojas prels. á más de la portada que está impresa suelta, 151 hojas fols. para los dos Discursos primeros, 131 para el tercero y cuarto, y 20 hojas de Tablas»): 4. ${ }^{\circ}$ - ¿ ¿[]2+1? A-T8; Aa-Sl8 Tt6. - ¿3 h.?, I-151 f., I-131 ff., 20 h. Va compuesta a plana y renglón con respecto a la princeps sevillana que imita, aunque -lógicamente-con materiales tipográficos distintos (lo más discriminante es la tipografía cursiva con abundantes rasgueos en las minúsculas, las iniciales grabadas de 7 y 8 líneas de arracada decoradas con laurel y los marmosetes de cierre de los dos últimos discursos, más pequeños y sencillos que en la edición genuina). Pero llama la atención que a pesar de mantener la doble secuencia de foliación de la princeps, al contrahacerla 
Por último, de la edición madrileña de 1620 con texto completo, aunque en apariencia sobreviven dos ejemplares, analizadas sus referencias catalográficas con la precaución recomendable, me inclino a pensar que se trata de una noticia imaginaria ${ }^{30}$ : el ejemplar de Toronto parece corresponder a un testimonio de la princeps, mútilo de portada al que le han asignado los datos de lugar y fecha más tardíos que figuran en los documentos de preliminares (bien tomados de la aprobación civil o de la fe de erratas, firmados en Madrid y en 1620). Esto mismo puede sugerirse para el o los ejemplares de Chile, aunque en este caso podrían corresponder a la edición contrahecha, por constar de 20 hojas finales de tabla.

Aunque su difusión editorial pudiera parecer exigua no es en absoluto despreciable -en particular por haber reclamado el interés comercial que toda edición contrahecha refrenda-; sin embargo, no deja de contrastar con la suerte que corrió El embajador en otros países hasta décadas muy posteriores ${ }^{31}$. No hay noticia de que fuera obra prohibida ni expurgada, pero lo cierto es que no se reeditó en España. Quizás la princeps sevillana -que por el número de ejemplares conservados debió de alcanzar una generosa tirada-, junto con la edición contrahecha -cuya fecha real y taller de imprenta no sabemos y que reclama un análisis tipobibliográfico-, cubrieran la demanda de mercado después de los diez años que regulaba el privilegio.

\section{BibliografíA}

Antonio, Nicolás, Bibliotheca Hispana Nova, sive hispaniorum scriptorum qui ab anno MD. Ad MDCLXXXIV floruere notitia..., Matriti, Apud Joachimum de Ibarra [et] Apud Viduam et Heredes Joachimi de Ibarra, 1783-1788, 2 vols.

CCPBE = Catálogo Colectivo del Patrimonio Bibliográfico Español. Ministerio de Cultura. Dirección General del Libro, Archivos y Bibliotecas: <http://www.mcu. es/bibliotecas/MC/CCPB/index.html>.

no percibieron su funcionalidad para la distribución exenta de los discursos finales y, por ahorrarse la última hoja en blanco del cuaderno T8, impusieron en su lugar las planas del fol. I de la segunda secuencia con el inicio del Discurso tercero (el «Sumario de su contenido»), quedando descabalada la perfecta correspondencia entre el texto y los cuadernos que se aprecia en la edición genuina. De ahí que a partir de esa segunda secuencia, especialmente desde el fol. 41, se pierda la composición a plana y renglón y las Tablas ocupen solo 20 hojas, en lugar de las 24 de la edición princeps, sin la protección final de la última hoja en blanco, obviamente, para ahorrarse un pliego y medio de papel, no desdeñable en una tirada cuantiosa. Corroborada la habitual fiabilidad de Salvá, podemos dar crédito también a su información sobre la portada, que en lugar de calcográfica sería simplemente tipográfica -con los datos editoriales contrahechos de Sevilla, Francisco de Lyra, 1520- e iría impresa en una hoja suelta (por ello de fácil pérdida), complementaria del medio pliego en el que remedarían los documentos de preliminares y la dedicatoria. Para todo ello me he servido de la descripción de Mercedes Fernández Valladares, en DialogycaBDDH (en prensa), a la que remito.

30. Conviene reparar en que no fue registrada por Pérez Pastor, 1891-1907, y tampoco Clemente San Román en su tesis doctoral, 1992, aportó testimonio alguno de su existencia.

31. Esta cuestión es objeto de un trabajo independiente que ha de considerarse complementario: Vian Herrero, en prensa $b$. 
Cinti, Bruna, Letteratura e política in Juan Antonio de Vera, ambasciatore spagnolo a Venezia (1632-1642), Venezia, Libreria Universitaria Editrice, 1966.

Clemente San Román, Yolanda, Impresos madrileños de 1566 a 1625, tesis doctoral, Madrid, Editorial Universidad Complutense, 1992.

Domínguez Guzmán, Aurora, La imprenta en Sevilla en el siglo XVII (catálogo y análisis de su producción), 1601-1650, Sevilla, Secretariado de Publicaciones de la Universidad de Sevilla, 1991.

Escudero y Perosso, Francisco, Tipografía hispalense: anales bibliográficos de la ciudad de Sevilla desde el establecimiento de la imprenta hasta fines del siglo XVIII, Madrid, Sucesores de Rivadeneyra, 1894, 2 vols.

Fernández-Daza Álvarez, Carmen, El primer conde de la Roca, Mérida, Editora Regional de Extremadura, 1995.

Fernández Valladares, Mercedes, «Descripciones tipobibliográficas de El Embajador de J. A. Vera y Figueroa, registro 325», DialogycaBDDH, <http://www.dialogycabddh.es/>, en prensa.

Ginarte González, Ventura, El Conde de la Roca. 1583-1658. Un diplomático extremeño en Italia, Madrid, Colegio Santa María del Bosque, 1990.

Gómez, Jesús, Tendencias del diálogo barroco. Literatura y pensamiento durante la segunda mitad del siglo XVII, Madrid, Visor Libros, 2015.

Graesse, Jean George Theodore, Trésor de livres rares et precieux ou nouveau dictionnaire bibliographique [Dresde, 1859-1860 y 2. ${ }^{a}$ ed., Berlín, 1922], Milano, Görlich Editore, 1950, vol. VII.

López-Cordón Cortezo, María Victoria, «Juan Antonio de Vera y Zúñiga (1583-1658). Modello di ambasciatori o specchio di trattatisti ?», en De l'ambassadeur: Les écrits relatifs à l'ambassadeur et à l'art de négocier du Moyen Âge au début du XIXe siècle [en línea], Roma, Publications de l'École française de Rome, 2015 (generado el 17 junio 2017). Disponible en: <http://books.openedition.org/ efr/2916>.

Mattingly, Garrett, Renaissance Diplomacy, London, Jonathan Cape, 1955.

Merluzzi, Manfredo, «Juan de Vera e I'Italia. Dall'ispirazione letteraria alla pratica diplomatica», en De l'ambassadeur: Les écrits relatifs à l'ambassadeur et à l'art de négocier du Moyen Âge au début du XIxe siècle, dir. Stefano Andretta, Stéphane Péquignot y Jean-Claude Waquet, Roma, Publications de l'École française de Rome. Disponible en <http://books.openedition.org/ efr/2918?lang=es> (1 junio 2017).

Ochoa Brun, M. Ángel, Historia de la diplomacia española. La Edad Barroca I, Madrid, Ministerio de Asuntos Exteriores y de Cooperación (Biblioteca Diplomática Española, Sección Estudios, 6), vol. VII, pp. 389-399. 
Palau y Dulcet, Antonio, Manual del librero hispano-americano, Barcelona / London, Librería Anticuaria / Maggs Bross 34, 1927, vol. VII. Esta primera edición se reimprime facsimilarmente en Madrid, Ollero y Ramos, 2004.

Palau y Dulcet, Antonio, Manual del librero hispano-americano. Bibliografía general española e hispanoamericana desde la invención de la imprenta hasta nuestros tiempos con el valor comercial de los impresos descritos, 2. ${ }^{a}$ ed. corr. y aum., Barcelona / Oxford, Librería Anticuaria de A. Palau / The Dolphin Book, 1948-1977, 28 vols., vol. XXVI (1975).

Pérez Pastor, Cristóbal, Bibliografía madrileña o Descripción de las obras impresas en Madrid (Parte primera: siglo XVI; parte segunda: 1601 al 1620; parte tercera: 1621 al 1625), Madrid, Tip. de los Huérfanos, 1891-1907, 3 vols.

Petey-Girard, Bruno, Polizzi, Gilles, y Tran, Trung (eds.), François Premier imaginé. Actes du colloque de Paris organisé par l'Association Renaissance-Humanisme-Réforme et par la Société Française d'Étude du Seizième Siècle (Paris, 9-17 avril 2015), Genève, Droz, 2017.

Pineda, Victoria, «La elocuencia del embajador: don Juan Antonio de Vera y Zúñiga y las Orationi militari de Remigio Nannini», Studia Aurea, 9, 2015, pp. 483-530.

Salvá y Mallén, Pedro, Catálogo de la Biblioteca de Salvá, Valencia, Imprenta de Ferrer de Orga, 1872, 2 vols. Hay reimpresión facsímil de Madrid, Julio Ollero, 1992, 2 vols.

Simón Díaz, José, Impresos del siglo XVII. Bibliografía selectiva por materias de 3.500 ediciones príncipes en lengua castellana, Madrid, CSIC, 1972.

Tamayo de Vargas, Tomás, Junta de libros, ed. Belén Álvarez García, Madrid / Frankfurt am Main, Iberoamericana / Vervuert, 2017.

USTC = The Universal Short Title Catalogue. Iberian Books. Books Published in Spanish or Portuguese or on the Iberian Peninsula before 1601 / Libros ibéricos. Libros publicados en español o portugués o en la Península Ibérica antes de 1601, ed. Alexander S. Wilkinson, Leiden / Boston, Brill, 2010. [Short-title colectivo de impresos ibéricos (siglos XV y XVI), accesible en la Base de datos USTC (The Universal Short Title Catalogue)]: <http://www.ustc.ac.uk/cicero/ search.php>.

Vera y Figueroa, Juan Antonio de, conde de la Roca, El enbaxador, Sevilla, Francisco de Lyra, 1620.

Vera y Figueroa, Juan Antonio de, conde de la Roca, El enbaxador, Sevilla, Francisco de Lyra, 1620, reimp. facs. Madrid, s. e. [Jesús Gironés, imp., Artes Gráficas Arges], 1947, apunte preliminar de José Manuel López Balboa.

Vera y Zúñiga, Juan Antonio de, conde de la Roca, El enbaxador, Sevilla, Francisco de Lyra, 1620, ed. facsímil, A Coruña, Órbigo, 2010. 
Vian Herrero, Ana, «Las prendas del diplomático: El embajador de Juan Antonio Vera y Figueroa (1620), un diálogo de especialización que conquista Europa», Madrid, Casa de Velázquez, en prensa a.

Vian Herrero, Ana, «Acercamiento a la difusión impresa europea de El Embajador de Juan Antonio Vera y Figueroa (1620)», en Actas del XI Congreso de la Asociación Internacional Siglo de Oro (Madrid, 10-14 julio 2017), en prensa b. 